\title{
Neutrophil chemotaxis and random migration in acute lymphoblastic leukaemia of childhood
}

\author{
Cellular and humoral aspects
}

SARAB AL-NAKEEB AND EILEEN N THOMPSON

Department of Child Health, Welsh National School of Medicine, Llandough Hospital, Penarth, South Glamorgan

SUMMARY The cellular and humoral components of the neutrophil chemotactic response were studied in 65 children with acute lymphoblastic leukaemia (ALL). An abnormality in both components was found during relapse. In remission the cellular component only was affected. Although less obvious than during relapse the abnormality persisted while all cytotoxic therapy was given, returning to normal several weeks after treatment had been stopped. The absence of significant infection in relapse in this series could be due to the fact that a remission was achieved within 3 weeks in all patients. However, a positive correlation between the migration index and incidence of bacterial infection during remission stressed the importance of impaired neutrophil chemotaxis in ALL.

The type of infecting organism has changed with more aggressive treatment of leukaemia, but bacterial infection remains a major problem and cause of death. ${ }^{1-2}$ Although severe granulocytopenia correlates reasonably well with susceptibility to infection, ${ }^{3-5}$ some patients may have severe and recurrent infective episodes despite adequate levels of circulating neutrophils. Certain aspects of neutrophil function-namely, phagocytosis and intracellular digestion-have been studied in leukaemia and found to be normal by some workers ${ }^{3-6}$ but other workers, using different methods, have shown a distinct decrease in these functions. ${ }^{7-9}$ Thompson and Williams ${ }^{10}$ demonstrated that $36 \%$ of leukaemic children in relapse and $25 \%$ of those in remission had depression of the intracellular digestive capacity of neutrophils, and in these children the clinical incidence of infection was greatest. In order to see if an earlier phase in neutrophil function was affected we studied cellular and humoral aspects of neutrophil chemotaxis and random migration. Tests were done in relapse and remission at different stages of the diseases, both on and off treatment.

Department of Child Health, Welsh National School of Medicine

SARAB AL-NAKEEB, research fellow

EILEEN N THOMPSON, senior lecturer

\section{Materials and methods}

65 children with acute lymphoblastic leukaemia (ALL) were studied, the values obtained were compared with those of age matched controls. The cellular aspects of chemotaxis was studied in $\mathbf{5 2}$ children. Six were in relapse ( 4 at diagnosis and 2 at the time of the first relapse, off all treatment); the other 46 children were in remission at the time of the study. 30 were studied on 39 occasions ( 7 tested more than once) while on maintenance therapy ( 10 had had treatment for $<3$ months, 6 for 3-6 months, 8 for 7-12 months, 8 for 13-24 months, and 7 for $25-36$ months). All these children were included in MRC treatment trials (UKALL I-V). They had all received cranial radiotherapy (2400 rad in 12 fractions over 21 days) between weeks 6 and 11 . Details of treatment given during the 14 days before testing for chemotaxis are given in Table 1. As maintenance chemotherapy consisted of a repetition of the 12-week module of cytotoxic drugs, all repeat tests were done at the same point in the cycle subsequently.

In 16 patients studies were done several months after all treatment had been stopped (8, 6-12 months; 8, 13-36 months).

The humoral aspect of chemotaxis was studied by testing the effect of activated sera obtained from 
Table 1 Treatment used in the 14 days before testing neutrophil chemotaxis

\begin{tabular}{|c|c|c|c|c|c|}
\hline \multirow[t]{2}{*}{ Drugs ( $m g / m^{2}$ per day) } & \multirow[t]{2}{*}{ No. of patients } & \multirow[t]{2}{*}{ No. of tests } & \multicolumn{3}{|c|}{ Chemotaxis (mean and range) } \\
\hline & & & Casein & Serum & $\begin{array}{l}\text { Random } \\
\text { migration }\end{array}$ \\
\hline \multirow{7}{*}{$\begin{array}{l}\text { 6-Mercaptopurine }(25)+\text { cranial radiotherapy* } \\
\text { 6-Mercaptopurine }(70) \\
7 \text { days after continuous 6-mercaptopurine }(75)+ \\
\text { weekly methotrexate }(10-15) \\
9 \text { days after 5-day course of methotrexate } \\
(12 \cdot 5)+6 \text {-mercaptopurine }(200) \\
17 \text { days after 5-day course of methotrexate } \\
(12 \cdot 5)+6 \text {-mercaptopurine }(200) \\
5 \text {-day methotrexate }(12 \cdot 5) \text { followed by } 7 \text { days } \\
\text { prednisolone }(40)\end{array}$} & 10 & 10 & $86(72-102)$ & $80(60-92)$ & $77(52-90)$ \\
\hline & 3 & 3 & $64(45-105)$ & $54(45-68)$ & $54(39-73)$ \\
\hline & 3 & 8 & $85(50-100)$ & 75 (47-96) & $59(30-75)$ \\
\hline & 3 & 4 & $65(21-93)$ & $64(39-86)$ & $61(47-83)$ \\
\hline & & & & & \\
\hline & 5 & 6 & 81 (55-99) & $73(53-96)$ & $65(53-90)$ \\
\hline & 6 & 8 & $74(49-118)$ & $73(44-123)$ & $61(35-90)$ \\
\hline
\end{tabular}

Mean \pm SD of matched controls for casein, $89 \pm 12$, serum $79 \pm 13$, and rardom migration $67 \pm 16$.

*2400 rad.

13 patients in relapse and 14 in remission (all drugs stopped at least 12 months earlier) on autologous remission and control neutrophils. The same cells were tested concurrently with control sera and the data expressed as a percentage difference.

Chemotactic assay. Chemotaxis was measured by Wilkinson's modification ${ }^{11}$ of the Boyden technique, and the index determined by the leading-front technique. ${ }^{12}$ The number of washed neutrophils used per assay was $2 \times 10^{5}$. Two attractants were used, casein $(5 \mathrm{mg} / \mathrm{ml})$ and $20 \%$ pooled normal sera. All the sera were activated by $2 \mu \mathrm{g} / \mathrm{ml}$ Escherichia coli endotoxin (Difco). Random migration was assayed by the same method using $20 \%$ activated sera in both compartments. Reproducibility of the method was excellent.

Clinical findings. 27 of the 65 children had completed 2 years of maintenance treatment, and in these the clinical data were reviewed to find the incidence of bacterial infection. Infection was graded according to severity (severe, moderate, or slight). Severe infections included septicaemia, pneumonia, and sustained febrile episodes of more than 48 hours' duration (temperature $>38^{\circ} \mathrm{C}$ ). The sustained febrile episodes were treated as septicaemic episodes, many of which quickly responded to antibiotics, although bacteriological data were negative. Common infecting organisms found were Staphylococcus aureus, haemolytic streptococci, Streptococcus pneumoniae, Haemophilus influenzae, $E$. coli, and Pneumoncystis carinii. Moderately severe infections included bronchitis, cellulitis, and those which required the patient to be admitted to hospital and be treated with parental antibiotics. Essentially the difference between severe and moderate infection was one of degree, the former being associated with general systemic effects, the latter with pyrexia and localised signs of infection. Minor infections affected the upper respiratory tract, inner ear, or skin and such patients were treated as outpatients. Any infection associated with severe neutropenia $(<0.5$ $\left.\times 10^{9} / 1\right)$ or of viral origin was excluded from this study.

\section{Results}

Cellular aspect. Results obtained from 6 patients studied in relapse and early remission are shown in Fig. 1. A reduction in chemotaxis was found in relapse compared with age-matched controls (Student's $t$ test $\mathbf{P}<0.001$ for both attractants). Remission values showed improvement but, with the exception of one, all values were still lower than the control mean. A difference between relapse and remission values was found (paired $t$ test, $\mathrm{P}<0 \cdot 05$ ).

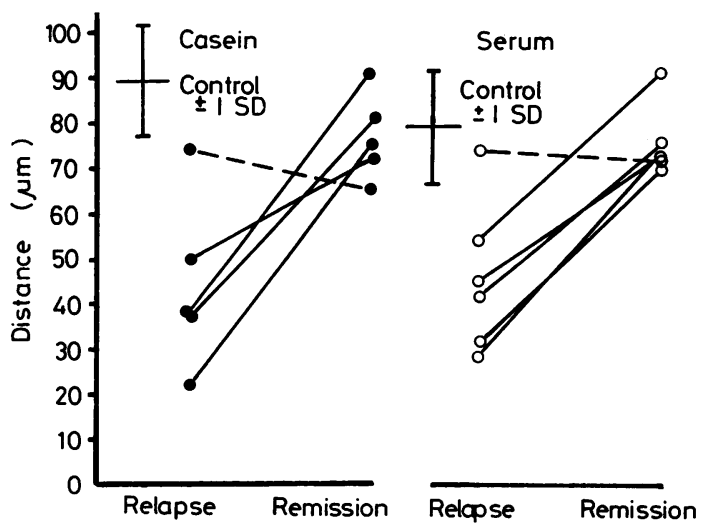

Fig. 1 Cellular aspect of chemotaxis in relapse and remission. Age matched control values (mean and 1 SD) are shown for both attractants to the left of the relapse values (relapse v. remission $P<0.05$ paired $t$ test, relapse $v$. controls $P<0.001$ Student's $t$ test $)$. 
Results of tests done at different stages of the disease (in remission) both on and off treatment are shown in Fig. 2. Although a pronounced improvement in chemotaxis occurred once a remission was achieved, this was not maintained after the first 3-month remission period. Thereafter, the overall mean at each study period was less than the control mean but was only significant in the 7-12-month period on treatment $(P<0.05)$. A wide range of values was obtained during each study period with continued improvement once all drugs had been stopped.
As the maintenance cytotoxic therapy used was not identical in each case, the effect of particular drugs given 14 days before testing chemotaxis was recorded (Table 1). The most pronounced effect was noted 9 days after a 5-day course of methotrexate and 6mercaptopurine (which had improved on day 17) and continuous 6-mercaptopurine at a daily dose of $\mathbf{7 5}$ $\mathrm{mg} / \mathrm{m}^{2}$. With the exception of low-dose 6-mercaptopurine, each drug had a variable individual effect.

These findings show that particular drug combinations and doses affect chemotaxis, but that this adverse effect decreases with time.
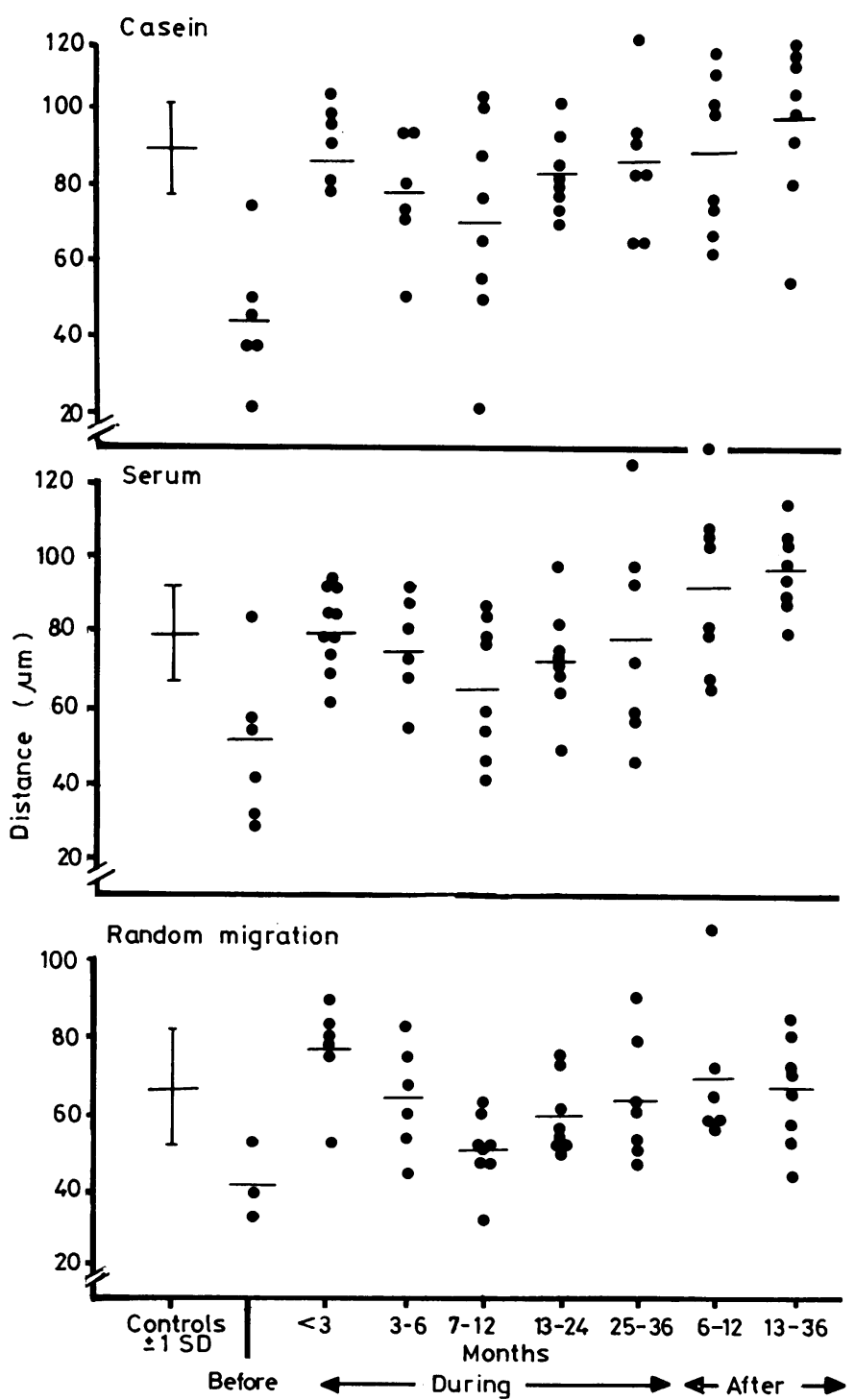

Fig. 2 Cellular aspect of chemotaxis before, during $(<3,3-6,7-12,13-24,25-36$ months), and after all treatment was stopped (6-12 and 13-36 months later). Initial inhibition of chemotaxis disappeared once a remission was achieved, but not maintained, particularly during the first 12 months of treatment. Thereafter there was improvement which continued once all treatment had stopped. 


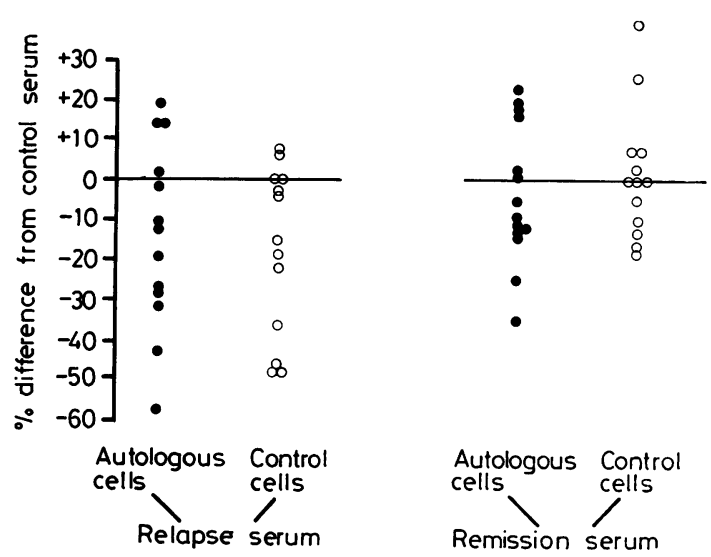

Fig. 3 Comparison of the effect of relapse and remission serum on chemotaxis of autologous (remission) and control neutrophils. The same cells were tested concurrently with control serum and the percentage difference found is used to express the results.

Table 2 Comparison of chemotactic index (casein and serum) and random migration, and the incidence and severity of infection in 26 children with leukaemia. Many had more than one infective episode (number of episodes shown in parenthesis). Five had no infections, 4 of whom had a normal chemotactic index.

\begin{tabular}{|c|c|c|c|c|c|c|}
\hline \multirow[t]{3}{*}{ No. of patients } & \multicolumn{4}{|c|}{ Chemotactic index } & \multirow{2}{*}{\multicolumn{2}{|c|}{$\begin{array}{l}\text { Random } \\
\text { migration }\end{array}$}} \\
\hline & \multicolumn{2}{|l|}{ Casein } & \multicolumn{2}{|l|}{ Serum } & & \\
\hline & $<80$ & $>80$ & $<70$ & $>70$ & $<60$ & $>60$ \\
\hline Total & 11 & 15 & 11 & 16 & 14 & 12 \\
\hline infections & $8(14)$ & $1(3)$ & $8(15)$ & $4(6)$ & $10(17)$ & $1(1)$ \\
\hline $\begin{array}{l}\text { With moderate } \\
\text { infections }\end{array}$ & $8(19)$ & $8(8)$ & $9(20)$ & $8(8)$ & $10(20)$ & $6(8)$ \\
\hline $\begin{array}{l}\text { With minor } \\
\text { infections } \\
\text { With no infections }\end{array}$ & $\begin{array}{l}9(43) \\
1(0)\end{array}$ & $\begin{array}{c}11(32) \\
4(0)\end{array}$ & $\begin{array}{l}9(47) \\
1(0)\end{array}$ & $\begin{array}{c}12(35) \\
4(0)\end{array}$ & $\begin{array}{c}12(50) \\
1(0)\end{array}$ & $\begin{array}{l}8(25) \\
4(0)\end{array}$ \\
\hline
\end{tabular}

Humoral aspect. The effect of relapse and remission serum on autologous remission and control cells is shown in Fig. 3. Relapse serum had an adverse effect on both autologous and control neutrophil chemotaxis (paired $t$ test, $\mathrm{P}<0.05$ and $<0.02$ respectively). However, remission serum did not have this effect.

The 8 patients in whom an adverse effect of relapse serum was found had several features at presentation, known to be associated with a poor prognosis ( 7 boys, liver $>4 \mathrm{~cm}$ in 4 , spleen $>4 \mathrm{~cm}$ in 2 , nodes $>2 \mathrm{~cm}$ in 5 , initial WBC count $>25 \times 10^{9} / 1$ in 2 ). Furthermore, 6 relapsed within 3 years of diagnosis, 2 of whom died soon afterwards.

Relationship of clinical findings to leucocyte migration. The incidence of infective episodes in relation to the chemotactic index in casein, serum, and random migration is shown in Table 2. The overall number of infections was greatest in children with a low chemotactic index $(<80,<70$, and $<60$ in casein, serum, and random migration respectively), but this was only significant in the case of severe infections $\left(\chi^{2}\right.$ test $P<0.01,<0.05$, and $<0.005$ in casein, serum, and random migration respectively). However, when the total number of infections (slight, moderate, or severe) per person was correlated with the migration index a significant value was obtained $(P<0.05$ in casein and random migration, $P<0 \cdot 1$ in serum).

\section{Discussion}

These studies demonstrate abnormalities in the humoral and cellular components of the chemotactic response of neutrophils from patients with ALL. Although neutrophil chemotaxis was abnormal initially and at later stages of the disease, while on treatment, the most pronounced abnormality was found during relapse. In relapse both humoral and cellular mechanisms were affected, but in remission only the cellular aspect was abnormal. Relapse serum had a deleterious effect on both autologous and control neutrophils. We do not know when the serum factor disappeared as all subsequent tests on leukaemic serum were done at a very late stage of remission. However, the cellular factor was assessed in relapse and in early, mid, and late remission and was found to be normal within 3 weeks of achieving a remission (that is, 6 weeks after starting treatment). In view of the brisk restoration of these values to normal it would seem likely that the relapse serum factor also cleared quickly. The nature of this factor, either circulating inhibitor or deficiency of essential substance, was not determined in this study. It is interesting that other workers in a study of patients with acute myeloid leukaemia ${ }^{13-15}$ demonstrated a circulating serum factor which affected neutrophil function (phagocytosis and bactericidal capacity but not chemotaxis, although cellular chemotaxis was abnormal) which improved once a remission was achieved. Furthermore the patients in whom the serum factor was present did less well than the others. Coiffier et al. ${ }^{15}$ suggested that this factor might be due to immune complexes which are known to inhibit phagocytosis ${ }^{16}$ and are said to indicate a poor prognosis in acute myeloid leukaemia. ${ }^{17}$ Similarly in our series, the presence of the serum factor was associated with a poor prognosis, despite the fact that all patients had received optimum therapy with early cranial prophylaxis.

With the exception of the 3- to 9-month period after cranial irradiation, neutrophil chemotaxis was 
not significantly impaired during remission. A wide range of values was found at each study point. This might be due to individual variation or to the effect of cytotoxic drugs. Unfortunately serial longitudinal studies were not possible. However, as chemotaxis improved after treatment had been stopped, and a positive correlation between frequency of infection and chemotactic index (while on therapy) was found, we felt it was likely that the cytotoxic drugs had an adverse effect on neutrophil migration. As the modern treatment of leukaemia is based on combination therapy given continuously or pulsed, it was not possible to study the effect of individual drugs. Furthermore, drugs given up to 14 days earlier might still have a residual effect on neutrophil function. Thus we were not able to determine the precise effect of a particular drug or combination in this study, except to comment that throughout the maintenance chemotherapy period, neutrophil chemotaxis was less efficient than when all the drugs had been stopped. None of these tests was done while the patient had evidence of clinical infection or if any other drug was being given. We attributed the suboptimal function during this time to the effect of the cytotoxic drugs.

It was interesting that the greatest decrease in function was found during the postirradiation period. It was at this time that Baehner et al. ${ }^{9}$ observed a decrease in phagocytosis and intracellular digestion of neutrophils in patients treated in this way. Whereas none of our patients had any severe infection during this period, it is known to be a high risk period for infection with a distinct chance of remission death. ${ }^{18}$ These workers attributed the infective morbidity and mortality to leucopenia, and found that by decreasing the dose of drugs during this period there was a reduction in morbidity and mortality. Although we did not find neutropenia during this stage in our patients, if defective neutrophil function is accompanied by a reduction in numbers then the infective risk to the individual could be intensified.

The introduction of more aggressive cytotoxic chemotherapy in the treatment of leukaemia has undoubtedly increased the risks from infection and remission death. ${ }^{19}$ Whereas the susceptibility to infection is known to be multifactorial, our study stresses that suboptimal neutrophil function may account for increased susceptibility to infection.

\section{References}

1 Nies B A, Bodey G P, Thomas L B, Brecher G, Freireich $E$ J. The persistence of extramedullary leukemic infiltrates during bone marrow remission of acute leukemia. Blood $1965 ; 26$ : $133-41$.
2 Bodey G P, Nies B A, Freireich E J. Multiple organism septicemia in acute leukemia: analysis of 54 episodes. Arch Intern Med 1965; 116: 266-72.

3 Silver R T, Beal G A, Schneiderman M A, McCullough $N$ B. The role of the mature neutrophil in bacterial infection in acute leukemia. Blood 1957; 12: 814-27.

4 Bodey G P, Buckley M, Sathe Y S, Freireich E J. Quantitative relationships between circulating leukocytes and infection in patients with acute leukemia. Ann Intern Med 1966; 64: 328-40.

5 Levine A L, Schimpff S C, Graw R G, Jr, Young R C. Hematologic malignancies and other marrow failure states: progress in the management of complicating infections. Semin Hematol 1974; 11 : 141-202.

- Braude A I, Feltes J, Brooks M. Differences between the activities of mature granulocytes in leukemic and normal blood. J Clin Invest 1954; 33: 1036-46.

7 Strauss R R, Paul B B, Jacobs A A, Simmons C, Sbarra A J. Metabolic and phagocytic activities of leukocytes from children with acute leukemia. Cancer Res 1970; 30: 480-8.

8 Gregory L, Williams R, Thompson E N. Leucocyte function in Down's syndrome and acute leukaemia. Lancet 1972; 1 : 1359-61.

9 Baehner R L, Neiburger R G, Johnson D E, Murrmann $S$ M. Transient bactericidal defect of peripheral blood phagocytes from children with acute lymphoblastic leukemia receiving craniospinal irradiation. $N$ Engl J Med 1973; 289: 1209-13.

10 Thompson E N, Williams R. Bactericidal capacity of peripheral blood leucocytes in relation to bacterial infections in acute lymphoblastic leukaemia in childhood. J Clin Pathol 1974; 27 : 906-10.

11 Wilkinson P C. Chemotaxis and inflammation. Edinburgh: Churchill Livingstone, 1974.

12 Zigmond S H, Hirsch J G. Leukocyte locomotion and chemotaxis. New methods for evaluation and demonstration of cell derived chemotactic factor. J Exp Med 1973; 137: 387-410.

13 Goldman J M, Th'ng K H. Phagocytic function of leucocytes from patients with acute myeloid and chronic granulocytic leukaemia. Br J Haematol 1973; 25: 299-308.

14 Wilkinson P M, Sumner C, Delamore I W, Geary C G, Milner $G \mathbf{R}$. Granulocyte function in myeloblastic leukaemia. Br J Cancer 1975; 32: 574-7.

15 Coiffier B, Frobert Y, Revol L. Polymorphonuclear function in acute myeloblastic leukaemia. Biomedicine 1977; 27: 94-6.

16 Koch C. Influence of endotoxin and complex bacterial antigens in the presence of serum factors upon the function of human neutrophils in vitro. Acta Pathol Microbiol Scand (C) 1975; 83: 195-202.

17 Carpentier N A, Lange G T, Fiere D, Fournie G J, Lambert $\mathbf{P} \mathbf{H}$, Miescher $\mathbf{P}$ A. Clinical relevance of circulating immune complexes in human leukemia. $J$ Clin Invest 1977; 60: 874-84.

18 MacLennan I C M, Peto J, Kay H E M. Analysis of treatment in childhood leukaemia. V. Advantage of reduced chemotherapy during and immediately after cranial irradiation. BrJ Cancer 1977; 36: 625-33.

19 Simone J V, Holland E, Johnson W. Fatalities during remission of childhood leukemia. Blood 1972; 39 : 759-70.

Correspondence to Dr E N Thompson, Department of Child Health, Welsh National School of Medicine, Llandough Hospital, Penarth, South Glamorgan CF6 1WX.

Received 17 May 1979 